\title{
A Case Report of 18q Deletion Syndrome and Xq Microdeletion
}

\author{
Yin Liu ${ }^{1 *}$, David Michelson ${ }^{1}$, Sheri Harder ${ }^{2}$ and June-Anne Gold ${ }^{3}$ \\ ${ }^{1}$ Department of Pediatrics/Child Neurology, Loma Linda University Children's Hospital, USA \\ ${ }^{2}$ Department of Radiology/Neuroradiology, Loma Linda University Medical Center, USA \\ ${ }^{3}$ Department of Pediatrics/Genetics, Loma Linda University Children's Hospital, USA
}

Submission: December 05, 2018; Published: December 20, 2018

*Corresponding author: Yin Liu, Department of Pediatrics/Child Neurology, Loma Linda University Children's Hospital, 11175 Campus Street, Coleman Pavilion Suite 11121, Loma Linda, CA 92354, USA

\begin{abstract}
Background: The differences of clinical features in 18q deletion syndrome may be explained by variations in breakpoints.

Case presentation: We report a case with a large terminal deletion of $18 \mathrm{q}$ and an Xq microdeletion. He carried most of the features of the 18q deletion syndrome. The genes involved in the Xq microdeletion had uncertain significance. He suffered from septic endocarditis of the mechanical mitral valve. It was notable that this patient with a complex genetic syndrome still demonstrated classic skin lesions that contributed to his diagnosis of acute endocarditis. No guidelines have been established regarding the management of anticoagulation in the setting of mycotic aneurysms from mechanical valve endocarditis. Our patient passed away from intracranial hemorrhage of the mycotic aneurysms.
\end{abstract}

Conclusions: Clinicians who familiarize themselves with the typical findings and complications of their patient's genetic syndrome will be more likely to recognize deviations and investigate them.

Keywords: 18q deletion syndrome; Xq microdeletion; Dysmorphic features; Intellectual disability; Congenital arcade mitral valve; Septic endocarditis; Mycotic aneurysms

\section{Background}

The differences of clinical features in $18 \mathrm{q}$ deletion syndrome may be explained by variations in breakpoints. We report a case with a large terminal deletion of $18 \mathrm{q}$ and a concurrently Xq microdeletion. The patient had an unusual disease course associated with congenital cardiac abnormality. There were several points in this case that were unexpected and therefore educational.

\section{Case Presentation}

The proband was the second child of a nonconsanguineous couple. He was born at term via an uncomplicated pregnancy with a birth weight of $3628 \mathrm{~g}$ ( $50^{\text {th }}$ percentile). At birth, he was noted to have a cleft palate, for which received corrective surgery within the first year of life. He was also diagnosed with congenital arcade mitral valve, which resulted in severe mitral stenosis and pulmonary hypertension. He had a mitral valve replacement at 5 years of age. He also had atresia of the ear canals and sensorineural hearing loss. Developmentally, he rolled over at 9 months, sat unsupported at 11 months, walked at 4 years, and rode a bike at 8 years.
He was first seen in the genetics clinic at 10 years of age. He was in special education classes and was going into the $4^{\text {th }}$ grade. A four-generation pedigree was obtained (Figure 1), which revealed no incidences of sudden cardiac death or arrhythmia. He was nonverbal but very socially engaged and prone to smiling. Clinical evaluation showed dysmorphic facial features (Figure 2). Other features not shown on the picture included repaired cleft palate with no evidence of cleft lip, absent uvula, and a tongue with an unusual central groove. He had a loud S1 from the mechanical mitral valve. There was no organomegaly. He had a small phallus and hypospadius with 2 urethral openings. The testes were descended bilaterally. He had flexion contractures in his lower extremities, especially in bilateral hamstrings and ankles. He held his hips in external rotation. He had tapered fingers with narrow nails. Supination was difficult. Eczema was present on bilateral wrist creases. The feet were small with intoeing and tight achilles tendons (Equinovarus). His muscle tone was increased, especially in the bilateral lower extremities. Reflexes were diminished but symmetric. He could not demonstrate a gait. 


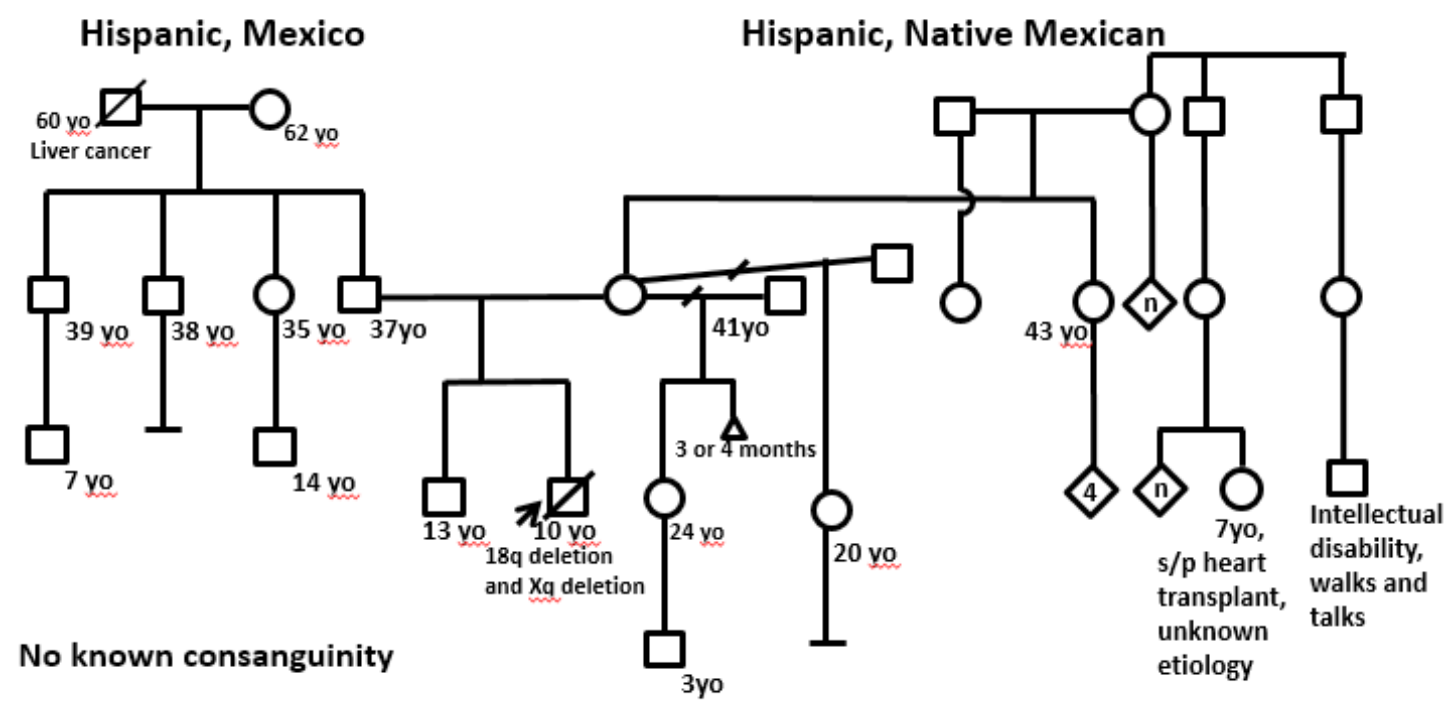

Figure 1: Four-generation pedigree. There was family history of congenital heart abnormalities and intellectual disability on the maternal side.
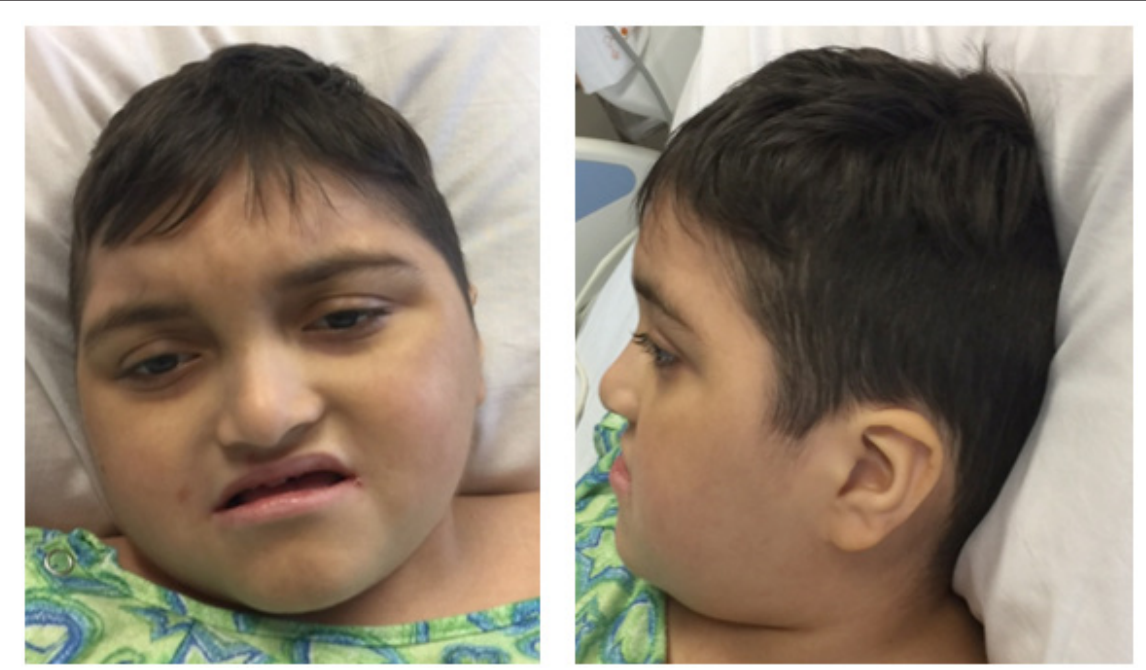

Figure 2: Facial features. Dysmorphic facial features included round facies, large eyes with up-slanting palpebral fissures, tapered skull, low set and posteriorly rotated ears, flattened midface, broad nasal root, flattened nasal bridge, beaked nasal tip, small mouth, down turning corners of the mouth, and malocclusion. Permission obtained from the father of patient.

A SNP microarray performed in his early childhood showed Xq21.31 (87,838,375-88,164,567) $\mathrm{x} 0$ and 18q21.3 1q23(54,690,270-78,014,123) x1. A 23.3 mega base terminal deletion from 18q21.31 to $18 \mathrm{q} 23$ was observed. This deletion was also identified by metaphase FISH studies using a $18 \mathrm{q}$ subtelemere probe (Abbott Molecular). The deleted interval involved approximately 115 known genes and is consistent with a diagnosis of "18q- syndrome". In addition, a 326 kilobase deletion at Xq21.31 was observed. The deleted interval includes the CPXCR1 gene. Abdominal ultrasound was essentially normal, showing normal kidneys. Orthopedic surgery diagnosed him with neuromuscular spasticity, equinovarus and cavovarus foot deformities, and tibial torsion. They recommended Botox injections, stretching, and casting. Tendon release and transfer surgeries to correct his foot deformities were also considered.

He was admitted to the hospital soon after the initial genetics visit for septic endocarditis of his mechanical mitral valve. Additional physical exam showed an extremely uncomfortable child, with flushing of his cheeks, scattered petechiae on his back, and Janeway lesions on both soles, his left index finger tip (Figure 3), and his left buttock. Trans-esophageal echocardiogram demonstrated a large vegetation on the mechanical mitral valve with associated regurgitation. He was started on appropriate antibiotics. Brain MRI showed multiple hemorrhagic bilateral cerebral infarcts concerning for septic emboli and mycotic aneurysms, confirmed on CT angiogram (Figure 4). His home 


\section{Juniper Online Journal of Case Studies}

Warfarin was switched to heparin continuous infusion for easy reversibility. The benefits of surgical valve replacement were felt to be outweighed by the risk of intracranial bleeding. However, during his hospitalization, he suddenly became unresponsive and an emergent head CT showed marked expansion of a right frontal hemorrhage. He passed away from cerebral herniation.

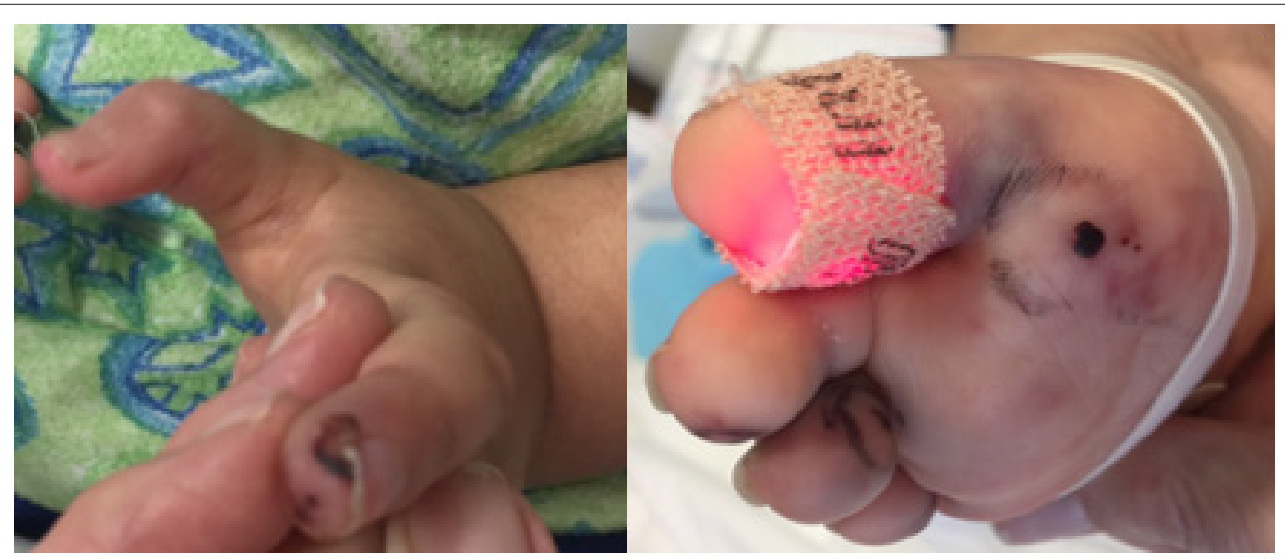

Figure 3: Janeway lesions of the patient's finger and sole. Non-tender, hemorrhagic, nodular or macular lesions, 3-5 mm in diameter, seen in association with infectious endocarditis. Permission obtained from the father of patient.

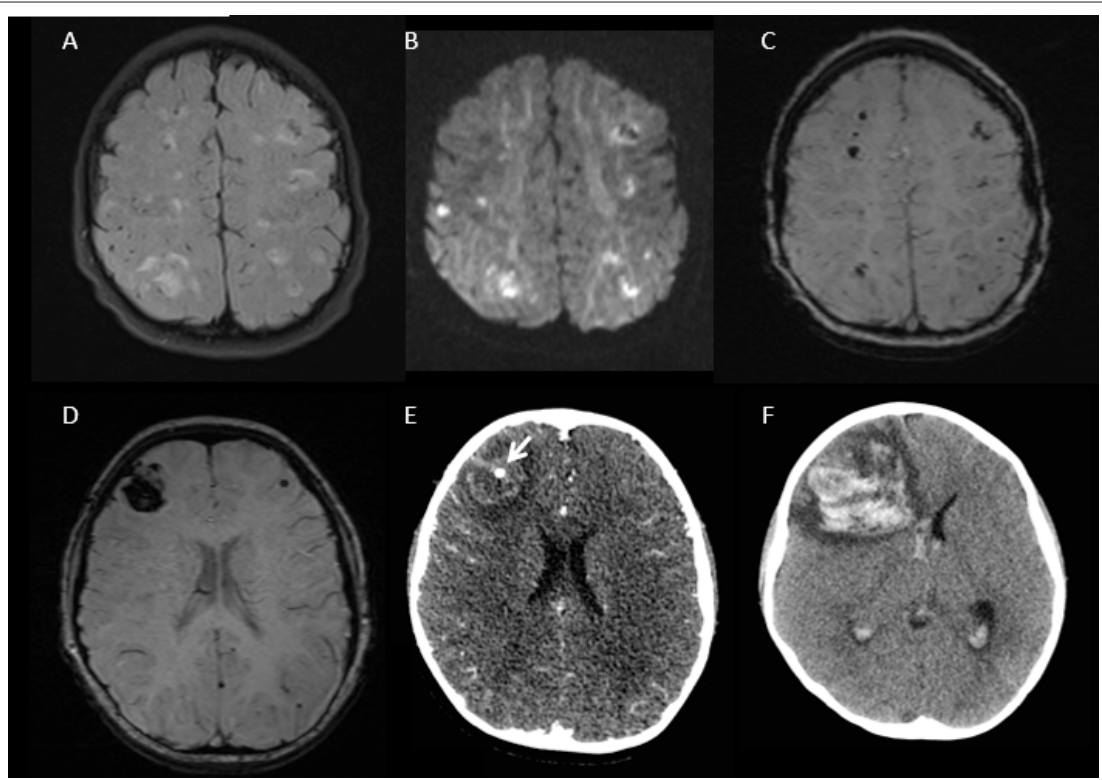

Figure 4: Imaging findings of the proband demonstrate multiple T2 hyperintense foci in the parasagittal cerebral hemispheres on the FLAIR sequence (A) with corresponding diffusion restriction on DWI (B) and associated hemorrhagic foci on SWI (C). The largest hemorrhagic focus is present in the right frontal lobe (D). CT angiogram reveals a small underlying mycotic aneurysm (E, white arrow). Follow-up CT head $(F)$ shows expansion of the right frontal hemorrhage with surrounding edema and mass effect and intraventricular extension of hemorrhage.

\section{Discussion and Conclusions}

Terminal deletion of the long arm of chromosome 18 is a relatively common cytogenetic abnormality, occurring incidentally in approximately 1 in 40,000 live births [1]. There have been many published cases [2-5]. Variation in breakpoints explains some of the differences in clinical features among those reports. Our patient had a large terminal deletion of 18q. Therefore, he carried most of the clinical features previously reported in this syndrome (Table 1). Deletion of the CPXCR1 gene, which our patient also had, has been studied for association with X-linked cleft palate, colorectal cancer, and uterine leiomyoma but does not currently have an established phenotype and may be benign [6-8].

Table 1: Clinical features associated with $18 \mathrm{q}$ deletion and their occurrence in our patient.

\begin{tabular}{|c|c|c|}
\hline \multicolumn{1}{|c|}{ Features } & Short stature \\
\hline \multirow{4}{*}{ Most Common Features } & Hypotonia \\
\cline { 2 - 3 } & Intellectual disability \\
\cline { 2 - 3 } & Foot anomalies \\
\cline { 2 - 3 } & + \\
\hline
\end{tabular}




\section{Juniper Online Journal of Case Studies}

\begin{tabular}{|c|c|c|}
\hline \multirow{4}{*}{ Feeding and Growth } & Cleft palate or high arched palate & + \\
\hline & Microcephaly & - \\
\hline & Short stature & + \\
\hline & Growth hormone deficiency & Unknown \\
\hline \multirow{5}{*}{ Appearance } & Midface hypoplasia & + \\
\hline & Low-set ears & + \\
\hline & Down turning corners of the mouth & + \\
\hline & Wide-set eyes & + \\
\hline & Short or up/down-slanted palpebral fissures & + \\
\hline \multirow{2}{*}{ Learning } & Leaning difficulties & + \\
\hline & Intellectual disability requiring special education & + \\
\hline \multirow{3}{*}{ Language } & Speech delay & + \\
\hline & Non-verbal & + \\
\hline & Receptive language markedly better than expressive & + \\
\hline \multirow{5}{*}{ Gross Motor Skills } & Delayed in gross motor development & + \\
\hline & Genu varum (Bow legs) & + \\
\hline & Scoliosis & - \\
\hline & Foot deformities & + \\
\hline & Joint problems, e.g. arthritis & - \\
\hline \multirow{2}{*}{ Fine Motor Skills } & Delayed and poor fine motor skills & + \\
\hline & Hand deformities & + \\
\hline \multirow{2}{*}{ Central Nervous System Myelination } & \multirow{2}{*}{ Dysmyelination with associated movement disorders, e.g. hand tremors } & + \\
\hline & & Hypomyelination \\
\hline \multirow{2}{*}{ Ears } & Ear canal stenosis or atresia & + \\
\hline & Hearing loss & + \\
\hline Epilepsy & Seizures & - \\
\hline Infections & Immunodeficiency, e.g. decreased IgA & Unknown \\
\hline \multirow{2}{*}{ Allergy and Asthma } & Asthma & - \\
\hline & Allergic reactions & - \\
\hline Skin & Eczema & + \\
\hline Thyroid & Hypothyroidism & - \\
\hline \multirow{2}{*}{ Heart Problems } & Innocent heart murmurs & - \\
\hline & Pulmonary stenosis & + \\
\hline \multirow{3}{*}{ Vision Problems } & Nystagmus & - \\
\hline & Short or long sight & - \\
\hline & Cortical blindness & - \\
\hline Hernias & Umbilical hernia & - \\
\hline Palate & Cleft lip and palate & + \\
\hline \multirow{3}{*}{ Genitalia } & Micropenis & + \\
\hline & Hypospadias & + \\
\hline & Labial hypoplasia & Not applicable \\
\hline \multirow{2}{*}{ Kidneys } & Vesico-ureteric reflux & - \\
\hline & Kidney stones & - \\
\hline \multirow{2}{*}{ Behavior } & Placid and affectionate mood & + \\
\hline & Temper tantrums, aggression, hyperactivity & - \\
\hline Puberty and Fertility & Proceeds as expected & Unknown \\
\hline
\end{tabular}

Notes: These features were extracted from the brochure published by Unique, named "18q deletions: from 18q21 and beyond". 


\section{Juniper Online Journal of Case Studies}

Minor heart conditions are common in patients with $18 \mathrm{q}$ deletion syndrome [9]. However, congenital arcade mitral valve has not previously been reported. Pulmonary valve stenosis is also common but need for surgical repair is rare [5]. The $18 \mathrm{q}$ deletion syndrome is commonly listed among the causes of hypomyelination [10] although most leukodystrophies show a more severe pattern of hypomyelination. The myelin deficiency seen on our patient's MRI was mild and patchy (not shown), in keeping with prior case reports.

Treatment of endocarditis in a patient with a mechanical valve includes antibiotics and surgical repair at an appropriate time [11]. Our patient was given appropriate antibiotics but was not able to undergo valve replacement given his high risk of complications and he died when there was expansion of the right frontal hemorrhage at the site of one of his known mycotic aneurysms. No guidelines have been established regarding the management of anticoagulation in the setting of mycotic aneurysms from mechanical valve endocarditis.

It is notable that this child with a complex genetic syndrome still demonstrated classic skin lesions that contributed to his diagnosis of acute endocarditis. Clinicians who familiarize themselves with the typical findings and complications of their patient's genetic syndrome will be more likely to recognize deviations and investigate them.

\section{Declarations}

Ethics approval and Consent to participate: Single case report did not meet the criteria for ethics approval at our institution. Informed written consent to participate and for publication was obtained from the father of the patient.

Consent to publish: obtained from the father of the patient.

Availability of data and materials: All data generated or analyzed during this study are included in this published article.

Author's contributions: Y.L. conceptualized and designed the study, collected data, drafted the initial manuscript, and reviewed and revised the manuscript. D. M. and S. H. collected the data, analyzed and interpreted the findings, critically revised and reviewed the manuscript for important intellectual content. J.G. coordinated and supervised data collection and interpretation, and critically reviewed the manuscript for important intellectual content. All authors approved the final manuscript as submitted and agree to be accountable for all aspects of the work.

\section{Acknowledgements}

We thank the patient and his family for allowing us to learn from their story.

\section{References}

1. Imataka G, Ohwada Y, Shimura N, Yoshihara S, Arisaka O (2015) Del(18)(q12.2q21.1) syndrome: a case report and clinical review of the literature. Eur Rev Med Pharmacol Sci 19(17): 3241-3245.

2. Kim YJ, Park TS, Han MY, Yoon HS, Choi YS (2015) A Korean case of de novo 18q deletion syndrome with a large atrial septal defect and cyanosis. Ann Lab Med 35(2): 272-274.

3. Guvenc O, Cimen D, Kaplan MB, Aslan E, Artac H, et al. (2015) A case with 18q deletion syndrome identified with $b$ cell absence and congenital heart disease. Genet Couns 26(4): 451-455.

4. Budisteanu M, Arghir A, Chirieac SM, Tutulan-Cunita A, Lungeanu A (2010) 18q deletion syndrome - A case report. Maedica (Buchar) 5(2): 135-138.

5. Cody JD, Sebold C, Heard P, Carter E, Soileau B, et al. (2015) Consequences of chromsome18q deletions. Am J Med Genet C Semin Med Genet 169(3): 265-280.

6. Braybrook C, Warry G, Howell G, Mandryko V, Arnason A, et al. (2001) Physical and transcriptional mapping of the X-linked cleft palate and ankyloglossia (CPX) critical region. Hum Genet 108(6): 537-545.

7. Abdul Aziz NA, Mokhtar NM, Harun R, Mollah MM, Mohamed Rose I, et al. (2016) A 19-Gene expression signature as a predictor of survival in colorectal cancer. BMC Med Genomics 9(1): 58.

8. Maekawa R, Yagi S, Ohgane J, Yamagata Y, Asada H, et al. (2011) Disease-dependent differently methylated regions (D-DMRs) of DNA are enriched on the $\mathrm{X}$ chromosome in uterine leiomyoma. J Reprod Dev 57(5): 604-612.

9. van Trier DC, Feenstra I, Bot P, de Leeuw N, Draaisma JM (2013) Cardiac anomalies in individuals with the $18 \mathrm{q}$ deletion syndrome; report of a child with Ebstein anomaly and review of the literature. Eur J Med Genet 56(8): 426-431.

10. Schiffmann R, van der Knaap MS (2009) Invited article: an MRI-based approach to the diagnosis of white matter disorders. Neurology 72(8): 750-759.

11. Nishimura RA, Otto CM, Bonow RO, Carabello BA, Erwin JP, et al. (2017) 2017 AHA/ACC Focused Update of the 2014 AHA/ACC Guideline for the Management of Patients with Valvular Heart Disease: A Report of the American College of Cardiology/American Heart Association Task Force on Clinical Practice Guidelines. J Am Coll Cardiol 70(2): 252-289.

\begin{tabular}{|l|}
\hline \multicolumn{1}{|c|}{ Your next submission with Juniper Publishers } \\
will reach you the below assets \\
- Quality Editorial service \\
- Swift Peer Review \\
- Reprints availability \\
- E-prints Service \\
- Manuscript Podcast for convenient understanding \\
- Global attainment for your research \\
- Manuscript accessibility in different formats \\
( Pdf, E-pub, Full Text, Audio) \\
- Unceasing customer service \\
Track the below URL for one-step submission \\
https://juniperpublishers.com/online-submission.php \\
\hline
\end{tabular}

